\title{
Chapter 1. Sustainable Development Goals and Measurement of Economic and Social Progress
}
Ravi Kanbur (T.H. Lee Professor of World Affairs, International Professor of Applied Economics and Management and Professor of Economics, Cornell University), Ebrahim Patel (Minister of Economic Development, South Africa) and Joseph E. Stiglitz (Professor of Economics, Business and International Affairs, Columbia University $)^{1}$

The report by the Stiglitz-Sen-Fitoussi (SSF) Commission raised fundamental questions about GDP as a measure of economic performance and social progress. The Sustainable Development Goals (SDGs) process put in train by the UN system proposes a number of goals and targets going beyond GDP that apply universally, to developing and developed countries alike. This chapter takes stock of the SDG process in relation to the general movement towards a broader perspective on the measurement of economic performance and social progress. Three central themes emerge. (1) The inevitable and enduring tension between the pull to broaden and expand indicators for assessing and monitoring economic and social progress in development on the one hand, and the imperative to keep a relatively small number of top-level indicators, in order to facilitate national discourse and policy making, on the other. The SDG list of 17 goals and 169 targets is useful as a platform from which to choose and narrow down, but choose we must at the national level. (2) National statistical offices must be given the governance independence and the financial resources with which to provide the framework for a data-based dialogue on economic and social progress at the national level. (3) Some aspects of the measurement of progress and development are global and beyond the sole remit of any one national statistical office. For these exercises, and as a conduit for providing support to national statistical offices, the international community needs to commit resources for the provision of this global public good. 


\subsection{Introduction}

The SSF Commission Report raised fundamental questions about GDP as a measure of economic performance and social progress (Stiglitz, Sen and Fitoussi, 2009, 2010). The critique included its neglect of: (i) non-market and social transactions; (ii) stocks and flows of physical, natural and human capital; and (iii) broad distributional issues. It also highlighted that GDP has many shortcomings even as a measure of market production. The OECD-hosted High Level Expert Group on the Measurement of Economic and Social Progress (HLEG) has been working on developing the recommendations of SSF, in particular regarding the suitability of GDP, and alternatives to it, for developing countries. At the same time, the Sustainable Development Goals (SDGs) process has been put in train by the UN system and has proposed a number of goals and targets as successors to the Millennium Development Goals (MDGs) after 2015, the MDG target date. It is thus becoming increasingly clear that the international community views progress in broader terms than just an increase in GDP. All of this links to, and feeds into, ongoing processes in developing countries to develop robust indicators of human, social and economic development.

This chapter takes stock of the SDG process in relation to the general movement towards a broader perspective on the measurement of economic performance and social progress. We begin in Section 2 with a brief history of the MDGs and their transformation into the SDGs. Section 3 considers the rationale for global targeting of the type found in the MDGs and SDGs in terms of their potential for setting norms. Section 4 translates this global norm setting into the national context and takes up, in particular, the "dashboard versus single index" question, as well as the question of how large a dashboard should be. Section 5 follows up with implications for statistics and statistical processes within countries. Section 6 addresses the question of global level monitoring, beyond a primarily national perspective. Section 7 concludes.

\subsection{MDGs and SDGs: A brief history}

The push to take a broad perspective on well-being, and especially in the measurement of development progress, goes back at least as far as the basic needs indicators and physical quality of life indexes in the 1970s. Both of these reflected the dissatisfaction with standard GDP as a measure of well-being. Basic needs went further than income and included access to food, water, shelter, clothing, sanitation, education and health care. Richard Jolly (1976) spoke of the "enthronement of basic needs." In 1980, Morris D. Morris (1980) proposed his Physical Quality of Life Index (PQLI) by taking a simple average of measures of literacy, infant mortality and life expectancy (Morris, 1980). And in the 1980s Amartya Sen developed his capability theory, which broadened the basis of social evaluation beyond income to "functionings and capabilities", defined as aspects of what human beings could be and do, (be in good health and perform paid work in safe conditions, for example, Sen, 1985).

Agencies like the World Bank still gave primacy to national income per capita as a measure of development but this began to change during the 1980s. The 1990 World Development Report was on poverty. It introduced the famous "dollar a day" poverty line, and the iconic number "one billion people around the world live below one dollar a day." But the move towards broader perspectives was given a big push by the launch of the Human Development Index (HDI) in UNDP's first Human Development Report in 1990. This index was a simple average of per capita income and measures of literacy and 
longevity. Although criticised for various technical reasons at the time of its release (Kanbur, 1990), the HDI proved to be enormously useful in (i) shifting attention to other development outcomes beyond income, such as health and education; and (ii) setting up a competition between countries on their HDI rank. The HDI has been modified and improved over the years to take account of the criticisms. But the core index still elicits great attention when it is published, and leads to national and international press coverage comparing different countries, which in turn can be used by civil society as a lever and a pressure on their governments.

The move towards multidimensional evaluation continued with a series of UN conferences throughout the 1980s and 1990s which emphasised gender, children, environment, food, and so on. This move was combined with the norm-setting potential of the HDI and culminated in the Millennium Development Goals, which derived from the Millennium Declaration, proclaimed by over 150 world leaders at the Millennium Summit in September 2000. The MDGs set out eight goals, and targets within each goal, up to 2015. The eight goals were: i) eradicate extreme poverty and hunger; ii) achieve universal primary education; iii) promote gender equality and empower women; iv) reduce child mortality; v) improve maternal health; vi) combat HIV/AIDS, malaria and other diseases; vii) ensure environmental sustainability; and viii) create a global partnership for development. Specific targets were put forward under each goal, including for example the iconic target 1A: "halve between 1990 and 2015 the proportion of people whose income is less than 1.25 USD a day."

As 2015 approached, progress was gauged relative to these targets. Perhaps not surprisingly, UN Secretary General Ban Ki-Moon proclaimed success and attributed it to the MDGs:

"The MDGs helped to lift more than one billion people out of extreme poverty, to make inroads against hunger, to enable more girls to attend school than ever before and to protect our planet. They generated new and innovative partnerships, galvanized public opinion and showed the immense value of setting ambitious goals. By putting people and their immediate needs at the forefront, the MDGs reshaped decision-making in developed and developing countries alike." (United Nations, 2015a, p. 3)

Whatever the truth of the causal link (considered in the next section), the scope of the goals was bound to be broadened when considering what to do after 2015 as interested parties brought to the fore key elements they considered were left out of the MDGs. In September, 2015, the United Nations General Assembly adopted Resolution 70/1, entitled "Transforming Our World: the 2030 Agenda for Sustainable Development", which stated:

"The new Agenda builds on the Millennium Development Goals and seeks to complete what they did not achieve, particularly in reaching the most vulnerable... In its scope, however, the framework we are announcing today goes far beyond the Millennium Development Goals. Alongside continuing development priorities such as poverty eradication, health, education and food security and nutrition, it sets out a wide range of economic, social and environmental objectives. It also promises more peaceful and inclusive societies... We are announcing today 17 Sustainable Development Goals with 169 associated targets which are integrated and indivisible. Never before have world leaders pledged common action and endeavour across such a broad and universal policy agenda." (United Nations, 2015b.) 
These seventeen goals are now under the following headings: i) no poverty; ii) no hunger; iii) good health and well-being; iv) quality education; v) gender equality; vi) clean water and sanitation; vii) affordable and clean energy; viii) decent work and economic growth; ix) industry innovation and infrastructure; $x$ ) reduced inequalities; xi) sustainable cities and communities; xii) responsible consumption and production; xiii) climate action; xiv) life below water; xv) life on land; xvi) peace, justice and strong institutions; and xvii) partnership. Compared to the eight MDGs listed above, the SDGs represent some constants (e.g. poverty), some bundling together (e.g. child mortality and maternal health), but mainly unbundling (e.g. poverty and hunger are separated out) and addition of new dimensions (i.e. a full range of environmental goals is added, as well as goals on inequalities, on peace, on urbanization, on employment, etc.).

The politics and pressures that led to an expansion of the scope of the eight MDGs to 17 SDGs (with its associated 169 targets and more than 230 indicators for these targets) are clear. Each constituency argued for its own particular goal to be represented in the overall list. Thus, for example, Doyle and Stiglitz (2014) argued, with success, for inequality reduction to be an explicit goal. Climate change was introduced as a separate goal but so, for example, was the goal to "conserve and sustainably use the oceans, seas and marine resources for sustainable development." The urban constituency got their goal, to "make cities and human settlements inclusive, safe, resilient and sustainable", and so on. The fact that everyone wanted the focal point of their concern (e.g. rule of law, inequality, urban, etc.) to be included in the list of SDGs is testimony to at least the belief in the power of these goals. Advocates believed that inclusion increased the chance of progress in their area of concern. But is 17 goals and 169 targets just too much, as some have argued? The answer to this depends on the objective of the exercise, i.e. the "goal" of goals-setting.

\subsection{The rationale of goal setting ${ }^{2}$}

There are at least two questions we can ask about the SDGs (as indeed about the MDGs). First, in what sense are they goals of the development process? Second, how, if at all, does goal setting aid the development process? Let us take these questions in turn.

Are the SDGs "goals" of development? Following Bourguignon et al. (2010), we can translate their questions on the MDGs to questions for the SDGs: i) Do the SDGs command (close to) universal agreement?; ii) Are the SDGs the final goals of development? Are they outcomes, outputs or inputs? ${ }^{3}$; and iii) How are we to weigh the SDGs relative to each other?

The first issue is perhaps easiest to answer in a formal and substantive sense. In a formal sense, the SDGs have been signed off on by political leaders of almost all of the countries in the world, and are encapsulated in a resolution of the United Nations General Assembly. Agreement does not get much more universal than that in an international setting. In a substantive sense, the SDGs as a package are likely to command consensus precisely because they are so wide ranging, so that many perspectives on development and well-being are brought into the 17 goals and 169 targets. But it is this comprehensiveness which leads to the next question, on what exactly they represent.

On the second issue, the 17 SDGs (both in their general statement, and in their further specification into detailed targets) are a mixture of the causal chain from inputs to outputs to outcomes. Take, for example, Goal 8, "promote sustained, inclusive and sustainable economic growth, full and productive employment and decent work for all." This goal, 
and its associated targets, mixes up inputs, outputs and outcomes, especially if we think back to the literature which took us away from GDP in the first place. Following Sen (1985), and Stiglitz, Sen and Fitoussi (2009), GDP is seen as an input, a means to an end rather than an end in itself. Yet target 8.1 is "Sustain per capita economic growth in accordance with national circumstances and, in particular, at least 7 per cent gross domestic product growth per annum in the least developed countries." Target 8.5 comes much closer to a final outcome variable in specifying employment and pay equality as objectives: "By 2030, achieve full and productive employment and decent work for all women and men, including for young people and persons with disabilities, and equal pay for work of equal value".

In the MDGs, Goal 8 on partnerships was often criticized for being a catch-all with little structure. In the SDGs, perhaps Goal 17, "Strengthen the means of implementation and revitalize the global partnership for sustainable development" takes on that role. This goal has no fewer than 19 targets, grouped under the subheadings of Finance, Technology, Capacity Building, Trade and Systemic Issues. Specific targets include such disparate components as: "Mobilize additional financial resources for developing countries from multiple sources"; "Significantly increase the exports of developing countries, in particular with a view to doubling the least developed countries' share of global exports by 2020"; and "By 2030, build on existing initiatives to develop measurements of progress on sustainable development that complement gross domestic product, and support statistical capacity-building in developing countries." The last of these is relevant to our discussion in Section 6 below, but the sheer complexity of Goal 17 is a testament to how the SDG process has catered to a very wide range of constituencies who have focused on their goal or target (be it inequality reduction, or primary education, or employment generation, or water and sanitation, etc.) and claim some legitimacy from it being present in some fashion in the list of SDGs, whether it is as input, output, or outcome.

On the third issue raised by Bourguignon et al. (2010), the large number of goals and targets, spread out along the input-output-outcome chain, raises obvious questions of evaluation and assessment. Supposing even that we were to agree on genuine outcome variables focused on human well-being, how are we to address the inevitable trade-offs? In their discussion of the MDGs, Bourguignon et al. (2010) pose the issue as follows:
"In a world of limited resources, it is likely that often progress on one MDG will have to be at the expense or postponement of another. Suppose country A rushes ahead on MDGx but falls behind on MDGy, whereas for country B the reverse is true. How is the MDG performance of the two countries to be assessed? Whose trade-off weights are to be used - country A's, country B's, or a universal trade-off determined internationally?"

The same questions can be asked with SDG substituted for MDG. The issue has become, if anything, even sharper with the broadening of the scope from the 8 MDGs to the 17 SDGs and associated targets. As argued below in Section 4, the issue is perhaps best resolved at the national level, by selecting which of the SDG targets and goals is most relevant in the specific country context, but this does not of course avoid the problem of trade-offs.

The second major question posed at the start of this section is how, if at all, does goal setting aid the development process? The answers to this question can be given at both the international level and the national level (Bourguignon et al. 2010). At the international level, goal setting can be useful from the technical point of view, 
quantifying the resources needed to achieve the selected goals. Thus, for example, Sachs (2005) used the MDG targets to estimate that, in order to achieve those goals, development assistance would have needed to increase to around 200 billion USD annually (compared to its level of around 65 billion USD in the early 2000s). Detailed sector by sector technical calculations underlie this overall figure, and the sector specific goals and targets again play a role in guiding and focusing these technical calculations.

UN Secretary General Ban Ki-Moon set out a second use of goal setting in the international context when, as quoted earlier, he said: "[The MDGs] generated new and innovative partnerships, galvanized public opinion and showed the immense value of setting ambitious goals". Given the difficulties of attribution, quantitative assessment of such claims is not easy. The assessments tend to be more qualitative in nature, as in McCarthy (2013):

"The greatest MDG successes undoubtedly concern health. The MDGs have invigorated multilateral institutions, such as the GAVI Alliance (formerly called the Global Alliance for Vaccines and Immunization), which seeks to achieve MDGs "by focusing on performance, outcomes and results." The goals have also inspired a huge increase in private-sector aid. Ray Chambers, a respected philanthropist and co-founder of a New York private equity firm, first learned of the goals in 2005. Since then, working with Sachs and others, Chambers has coordinated a worldwide coalition of policy, business, and NGO leaders in an effort to help the developing world meet the goal for malarial treatment and prevention. Thanks in part to this global effort, malaria-related mortality has dropped by approximately 25 percent since 2000, with most of those gains probably occurring since 2005. Many pharmaceutical companies have also put forth major efforts to make their medicines more widely available in poor countries, and new initiatives are continuing to take shape. The MDG Health Alliance, founded in 2011, is comprised of business and NGO leaders around the world working toward the MDG health targets, including the elimination of mother-to-child HIV transmission."

Many sectors can no doubt claim successes of this type, which might also explain the dramatic increases in goals and targets by the time the MDGs were transformed into the SDGs.

The reasons for the dramatic increase in goals and targets in the SDGs are: i) the inclusive process used to develop the SDGs; and ii) the SDGs' broadening of perspective to include the environment and human rights agendas. Perhaps the appropriate way to think about the SDGs is indeed in a broad perspective, as a platform which provides global civil society with a base from which to organise around one of the many issues in the SDGs. It also provides national civil society organisations an entry point in the dialogue with their own governments. The fact that the SDGs are sanctioned, after a fashion, by the community of world leaders gives national civil society a starting point in their national organising, if they care to use them in that way, although one danger is that the discussion focuses so much on measurement that discussion on how to actually achieve the goals gets drowned out. But what this highlights is that, ultimately, the SDGs have to be brought to the national level, and be translated into specific goals and targets as a compact between governments and their populations. Here, technical operationalisation and political salience are both needed to go from 17 goals and 169 targets to a dashboard which can capture key national political concerns and can be monitored and communicated easily. 


\subsection{Implications for national policy}

A heterogeneous mixture of 17 goals and targets, negotiated between and balancing the interests of a wide range of global groups, cannot provide specific guidance for national policy. That guidance has to come from national concerns and national processes, although the SDGs can provide a useful frame of reference as needed. In the opening statement to the HLEG workshop on "Measurement of Wellbeing and Development in Africa", Ebrahim Patel, South Africa's Minister of Economic Development and one of the co-authors of this chapter, posed two questions as a national policy maker, recognising both the centrality of GDP and the depth of its problems:

1. Can we find a single composite index to replace GDP?

2. If not, how big should the dashboard of indicators be and what should be on it (apart from GDP or, as alternatives, measures of household income or consumption)?

As argued in Stiglitz, Sen and Fitoussi (2009), GDP has been misused. In his presentation to the HLEG workshop, Lorenzo Fioramonti presented several directions in which GDP could be modified and supplemented, or even supplanted, from an African perspective. ${ }^{5}$ As he argued, GDP has become a "proxy for everything." However, this could be because, in effect, GDP has stepped into a vacuum because of its simplicity and its correlation with at least some other dimensions of well-being. Despite its weaknesses, GDP has proved useful as a practical tool to policy makers. While the critiques of GDP have been sharp, proposals to replace it have been less sharp - as reflected perhaps in the 17 goals and 169 targets which have emerged from the SDG process. This broad a range of goals and targets cannot make for practical policy making.

So, should GDP be replaced by an alternative composite index? There are of course many possible candidates. Sticking initially to the income sphere, we could consider measures of national poverty, although there are many possible poverty indices which can be presented, ranging from absolute poverty to relative poverty. Or we could, still in the income domain, rely on a measure of per capita national income corrected for income inequality (e.g., we could use as our composite index, per capita income multiplied by one minus the Gini coefficient); then if income inequality rises holding GDP constant, "corrected" GDP would fall. But even here, Joseph Stiglitz argued in his presentation to the HLEG workshop that the Gini coefficient may be too simple a measure of inequality, hiding important movements within the income distribution (for example changes in the income shares at the very top of the income distribution). ${ }^{6}$

But all of this is still in the income domain. Various versions of the UNDP's Human Development Index (HDI) - starting from the basic one which takes a simple average of per capita income, literacy and life expectancy - have attempted to move beyond the income space. As noted earlier, the HDI proved quite successful in the international domain in setting up comparisons across countries and giving ammunition to each country's civil society to spur healthy competition between governments to advance on the components of the HDI. Of course, the components in the basic HDI are national averages and do not take into account the distribution around the average. For this, more sophisticated, distribution sensitive, component values can be developed before averaging across the three dimensions. The "inequality-adjusted HDI" (UNDP, 2016) can give markedly different rankings and, for some purposes, can become a focal point of norm setting. However, the greater the sophistication of each sub-index, and thus of the index as a whole, the more the index is likely to lose its power as a tool of communication. 
An example of an index which combines multidimensionality of components with a focus on poverty or deprivation, is the Multidimensional Poverty Index (MPI), developed by Alkire and Foster (see Alkire, Foster et al. 2015) and presented by Sabina Alkire at the same HLEG workshop. ${ }^{7}$ Here the issues are the selection of dimensions, the specification of the cut-off in each dimension to identify deprivation, and then the normative choice of the number of dimensions in which an individual must be deprived in order for that individual to count as deprived overall. Such reduction of complex multidimensionality into a single index has elicited critiques, which can be interpreted more generally as critiques of any composite index and as support for a dashboard of indicators:

\begin{abstract}
"Recognizing that poverty is not just about lack of household command over market goods does not imply that one needs to collapse the multiple dimensions into one (uni-dimensional) index. It is not credible to contend that any single index could capture all that matters in all settings.....But when one faces a tradeoff, because a policy spans more than one dimension, those with a stake in the outcomes will almost certainly be in a better position to determine what weights to apply than the analyst calibrating a measure of poverty." (Ravallion, 2011, p. 247).
\end{abstract}

In his presentation at the HLEG workshop, Joseph Stiglitz also argued that a dashboard was preferable to a composite index. Different numbers are useful for different purposes, and local context is important in selecting which numbers matter for what.

This then leads to Ebrahim Patel's second question: how big should the dashboard be, and what should be on it? On the number of goals and targets, the answer is of course country specific, but there may be some consensus developing on how many. It is generally agreed, and it was the view expressed by all participants at the HLEG workshop, that the SDGs are good as a platform, but 169 targets is way too large a number of indicators to be useful as a "top of the dashboard" list in a national dialogue. The Genuine Progress Indicator (Talberth, Cobb and Slattery, 2006), for example, has not really taken off - is it because it has 26 component parts? The Mexican government uses income poverty as well as deprivation on seven other dimensions to monitor national well-being (CONEVAL, 2010). The case for a limited number of indicators is also made in the report of the Atkinson Commission on Global Poverty (Atkinson, 2016). The general point is that the number of top level entries on a dashboard for measuring and monitoring wellbeing and development should not be too large, and there is a case to be made for the number to be below 10 and perhaps around 7, depending on country context, although some would argue that even that may be too many.

What should be on the dashboard is also, of course a country specific question. For South Africa, for example, key well-being indicators apart from GDP would have to include the employment dimension. Throughout Africa, the use of unemployment as an indicator is fraught with problems, as argued by Baah-Boateng at the HLEG workshop. ${ }^{8}$ The high levels of informality mean that the standard ILO measurement of unemployment does not capture the essence of lack of productive work. In South Africa there has been an argument for using employment rather than unemployment as a lead indicator. ${ }^{9}$ Again in South Africa, the issue of income inequality is also front-and-centre in policy debates and in the national consciousness. But which measure of inequality - the Gini coefficient, or the income share of the top $\mathrm{X} \%$ ? And which metric of household material conditions, e.g. household consumption or income, net or gross of taxes, per capita or equivalised? Access to basic services is also a leading issue in South Africa, but here we risk getting into a proliferation of dimensions including education (different levels), health-care and 
housing. Perhaps for these social dimensions one could have a multidimensional deprivation index as suggested by Alkire, Foster et al. (2015). And none of this touches on longer term environmental degradation concerns. Further, in South Africa, disaggregation by race is central to the policy dialogue, as is disaggregation by gender.

Ultimately the choice of what should figure on a dashboard is a national policy decision with no simple technical methodology to the rescue. But if, following Ebrahim Patel's question, we were forced to prioritise to, say, five indicators, what would they be? For a country like South Africa, and other countries in Africa, perhaps the following indicators would be prominent:

1. Per capita income.

2. Income Inequality and poverty.

3. Employment.

4. Multidimensional Deprivation Index based on access to basic public services.

5. Long-term environmental degradation.

Throughout, these indicators would need to be disaggregated by race and by gender, and perhaps by other categories such as age; so, because of these breakdowns by population groups, the sense of a small number of entries on the dashboard may be somewhat illusory. Furthermore, there are sub-indicators behind these key indicators, such as wages under employment, or individual dimensions of poverty in the multidimensional deprivation index, or various aspects of long-term environmental degradation. And there may well be disagreements even on the selection of the top 5 key indicators. What is needed is a national level discourse that takes the SDGs as a platform and then fashions a dashboard that meets national needs and priorities, as well as the statistical capacity of each country to generate the data needed. ${ }^{10}$

\subsection{The role of statistics at the national level}

Statistics have power, and are political. In his presentation to the HLEG workshop Ravi Kanbur discussed the role that statistics had played in colonial rule, in the struggle for independence, and in post-independence governance in India. ${ }^{11}$ In the nineteenth and early twentieth centuries, the India Office - the British government department administering Indian affairs - was required to present an annual report to Parliament on the "Moral and Material Progress and Condition of India." Indeed, John Maynard Keynes, in his first job out of university, served in the India Office and edited the report for 1906-07.

But the same device which was used by the colonisers to convince themselves of their "mission civilisatrice" was turned on them by those struggling for independence. The National Planning Committee of the Indian National Congress, headed by India's future Prime Minister Jawaharlal Nehru, produced a report in 1936, referred to by Nehru in his book Discovery of India: “... there was lack of food, of clothing, of housing and of every other essential requirement of human existence." Independence was needed "to ensure an adequate standard of living for the masses, in other words, to get rid of the appalling poverty of the people". Nehru wrote these words in prison, having been put there by the British authorities for his role in the Quit India movement of 1942. But a generation of Indian analysts had been using official statistics and doing their own surveys to bolster, in effect, the empirical case for independence.

Given this role of statistics in the Indian independence struggle, and especially the role played by statistics on well-being of the population, it is perhaps not surprising that 
special attention was paid in India after independence to data on the distribution of consumption and poverty and on access to public services. The Indian National Sample Survey (NSS) is the longest running household survey in developing countries, stretching back to the 1950s. Every release of data is accompanied by lively debate and discussion on the key statistics as providing an assessment of policy outcomes and directions for the future (Deaton and Kozel, 2005).

The SDG process, and the emphasis given to goals, targets and indicators in that process, has thrown into sharp relief the generation and use of statistics in developing countries, particularly in Africa. This includes the accessibility and availability of data to researchers and the population at large. In his presentation to the HLEG workshop, Pali Lehohla, former Statistician General of South Africa and head of Statistics South Africa, emphasised that GDP provided a good framework for what it measured, but that it was badly used. In principle, for example, a Social Accounting Matrix (SAM) framework could be used to enrich distributional discussions anchored on GDP. These sentiments were echoed by Rashad Cassim, now Deputy Governor of the South African Reserve Bank and former Head of National Accounts in Statistics South Africa:

“... getting GDP measures and its components right is not trivial and there are many challenges that a middle-income country like South Africa, let alone developing countries, face in getting a set of conventional economic indicators right... Tensions are not only between social and economic data but between high frequency economic data and structural long term economic data. Put differently, should we gear up our statistical infrastructure to track, as accurately as we can, the business cycle or sacrifice this for something else - like putting more resources into estimating the value added of the informal sector, conduct area sampling to better understand small enterprises? "12

Cassim went on to elaborate upon a number of trade-offs faced in practice by national statistical offices, including those involving quality of data, even in the relatively standard area of national accounts, let alone in expanding their remit as seemingly required by the SDG process so as to track and monitor a vast number of indicators.

These concerns were further underlined by Daniel Masolwa of Tanzania's National Bureau of Statistics, who emphasised the cost of running regular establishment and household surveys, as well as specialised surveys on informal transactions such as unrecorded cross-border trade. ${ }^{13}$ Chukwudozie Ezigbalike, Chief of the Data Technology Section of the UN Economic Commission for Africa estimated that, in 2005, the cost of running a survey of 3000 households exceeded 500000 USD. ${ }^{14}$ However, he also argued that use of new technology, as well as improving and expanding administrative data, could initiate an African data revolution in which agricultural and other data could be collected rapidly and at low cost.

For many low income countries, these financing needs have driven their statistical offices into the hands of donors who have their own and often shifting priorities. The entire statistical system of some low income countries is geared to the statistics that donors wish to collect. This may be no bad thing if the government is encouraged, for example, to collect gender disaggregated data on well-being. But, as a general rule, statistics in democracies should be driven by data the government has to collect to satisfy the monitoring and planning needs on behalf of the population.

The data revolution and the use of new technology emphasised by Ezigbalike is not simply a technical fix to collect relevant data more cheaply. It also highlights the role that 
civil society and the population at large can play in the statistical discourse, taking it beyond the preserve of technical experts. A key requirement is of course the independence of statistical systems from partisan politics. But, beyond this basic governance requirement, we are back again to the question of how many top-level indicators there should be in a national dashboard. It can be argued that too many and too complex a set of indicators would actually be deleterious to an informed debate in society, including the vigorous participation of civil society.

There can, and there always will be, specialised interactions on specific sectors, and resources will move back and forth to assess and monitor progress and prospects in these areas to reflect the ebb and flow of political interest. But if a relatively small number of top-level indicators can be agreed upon, for example the five outlined in the previous section, national discourse can focus on these, and adequate resources can be made available to the national statistical office to provide the data base for such discussion. The provision of additional resources for data collection, as well as helping develop tools and methodologies, is an essential contribution needed from the international community. ${ }^{15}$

\subsection{Measurement at the global level}

The SDGs are goals developed at the global level, but their major significance is at the national level, as laid out in the previous sections. The national discourse is, of course, central to the development process, but there are also uniquely global dimensions to key elements of the SDGs, for which we have to take a perspective which goes beyond the national. This triggers the need of establishing internationally agreed statistical standards, for which global and regional organisations such as the ILO, the OECD or Eurostat (at the European level) have a major role to play. ${ }^{16}$ We consider three such examples - global poverty, global inequalities, and global climate change.

SDG 1.1, the first quantitative target of the first SDG is: "By 2030, eradicate extreme poverty for all people everywhere, currently measured as people living on less than 1.25 USD a day." This is also the first of the new "twin goals" of the World Bank. The usual operational definition of "eradicate" is to reduce it down to $3 \%$. But note that this is a global goal, in other words it is a goal for a global measure of poverty. This immediately raises the question of how global poverty is to be measured. Dean Joliffe's presentation at the HLEG workshop set out the World Bank's current thinking and the dilemmas it raises. ${ }^{17}$ The report of the Atkinson Commission on the Measurement of Global Poverty (2016) also takes up the issue in more detail.

Focusing on monetary measures of poverty, two questions arise in getting a global count of poverty. First, how are nominal incomes and consumption around the world to be turned into comparable real income measures? Converting local currency values into a common currency globally by using official exchange rates (say to the US dollar) opens up the question of whether these exchange rates measure true cost of living differences between different countries. In general they do not, because market exchange rates reflect only traded commodities and may also reflect financial flows and government policy interference in market exchange rates. To overcome these problems, the World Bank and others use Purchasing Power Parity (PPP) exchange rates, the use of which is itself steeped in controversy (Deaton, 2010; Ravallion, 2014), a controversy which reignites every time a new set of PPP exchange rates is published. The issue is not whether to use PPPs or not, but the methodology underlying their calculation. And, of course, PPPs are meant to be conversion factors for some aggregate basket of goods and services, rather than being representatives of what the poor consume. 
The second question arises even if we were to successfully arrive at a true distribution of real income in the world as a whole. Where then do we draw the poverty line? There are various conceptual bases, for example starting from basic capabilities inspired by Sen and working down from those to a line in the income space (e.g. Reddy and Pogge, 2010). But, as a practical matter, the World Bank has constructed its global poverty line using as inputs various national poverty lines (Ferreira et al. 2015), it being presumed that these national poverty lines reflect a range of actual normative perspectives. This method led to a poverty line of 1.25 USD per person per day at $2005 \mathrm{PPP}$, which is the line stated in SDG 1.1, and a line of 1.90 USD at 2011 PPPs, as set out in Ferreira et al. (2015). The two lines do not lead to a big difference in the global poverty count (just over $14 \%$ of the world's population).

Turning now to inequality, SDG 10 is "Reduce inequality within and among countries", which actually raises an interesting set of issues which go beyond statistics and measurement, to the conceptual. Take for example the case of income inequality. Overall inequality among all individuals in the world can be decomposed into inequality between countries and inequality within countries. ${ }^{18}$ Inequality between countries is the inequality of the world distribution of income if each person in a country was given that country's average income - in other words, it is the inequality that would be left if within country inequality were eliminated in each country. The difference between this inequality and total inequality is then the contribution of within-country inequality to total world inequality.

What do the numbers look like on this decomposition of global inequality into betweencountry and within-country components? For the "mean log deviation" measure of inequality (which takes a value of zero when everyone has the same income, rising as incomes become more unequal), Lakner and Milanovic (2015) find that the betweencountry contribution was $77 \%$ in 2008 , down from $83 \%$ in 1988 . The overall global inequality index fell by $10 \%$ over this same 20 year period. These trends capture broadly what we know about global inequality trends. Within country inequalities have been rising in the large countries of Asia (Kanbur and Zhuang, 2012) and, because of their population size, this effect dominated the falling within-country inequality in Latin America. However, low income countries have grown much faster than high income countries, with the result that between-country inequality has fallen. The overall combination of these effects has been a fall in global income inequality.

These patterns - rising within-country inequality but falling between-country inequality raise the conceptual question of how, if at all, we weight these components of inequality. The between-country component is numerically much larger - the wellbeing chances of an individual are predominantly determined by the probability that they are born in this or that country. Thus from this perspective it is as important to monitor both betweencountry inequality and within-country inequality, and SDG 10 recognizes this imperative, although, perhaps surprisingly, no indicators in the 'global list' agreed by the UN Statistics Division refer to this between-country element.

Our third example of global measurement is the most obvious case where monitoring and assessment at a global level is crucial, i.e. climate change and its determinants. Although the short-term consequences of climate change can vary by locality - rising sea levels will devastate small island states, but rising temperatures may be beneficial to some temperate zones - the long-term consequences pose an existential threat to humanity, especially if certain tipping points are reached. These global tipping points are precisely that, i.e. global. The extent to which we are approaching them is determined not just by 
greenhouse gas emission by this or that country, but by global emissions in total. Similarly, the carbon sequestration potential of the planet is determined by total forest cover in the world, and weather systems around the world are linked to each other.

Thus while action on adaptation and mitigation in response to climate change will necessarily have a national component, the monitoring and assessment is equally necessarily global in nature. Such global monitoring is not as prominent as it should be in the SDG platform. Under SDG 13, it can be glimpsed in the target SDG 13.3, "Improve education, awareness-raising and human and institutional capacity on climate change mitigation, adaptation, impact reduction and early warning", or perhaps in target 17.19, the last target of the $17^{\text {th }}$ and last SDG, on partnership for sustainable development, "By 2030, build on existing initiatives to develop measurements of progress on sustainable development...". However stated, global monitoring of global climate change is surely a key component of the measurement of economic and social progress, and common global measurement instruments and accounting systems such as the System of Environmental Economic Accounting (SEEA) are crucial in developing common indicators. It is indeed the classic public good, like measuring and monitoring global poverty or global inequality.

\subsection{Conclusion}

The Stiglitz, Sen and Fitoussi (2009) report came after the MDGs, but well before the SDG process got under way. The authors' insistence on going beyond GDP meshed well with, and greatly contributed to, the broadening of the agenda on the measurement of economic and social progress. But that report did not give as much emphasis as appropriate to issues which arise in developing countries. The SDG process does indeed have a focus on development, although of course it is meant to encompass developed countries as well, and the time is right for us to take stock of where we have come and where we need to go in measuring economic and social progress in developing countries and globally. This chapter attempted such an exercise.

Three central themes emerge from our discussion, and from the HLEG workshop on which our discussion is based. First is the inevitable and enduring tension between the pull to broaden and expand our indicators for assessing and monitoring economic and social progress in development on the one hand, and on the other the imperative to keep a relatively small number of indicators at the "top level of the dashboard", in order to facilitate national discourse and policy making. The first pull is what explains the expansion of the SDGs from the 8 MDGs to 17 Sustainable Development Goals and 169 targets. This list is useful as a platform from which to choose and narrow down, but choose we must at the national level.

Second, national statistical offices must be given the governance independence and the financial resources with which to provide the framework for a data-based dialogue on economic and social progress at the national level.

Third, some aspects of the measurement of progress and development are truly global and beyond the remit of any national statistical office. For these exercises, and as a conduit for providing support to national statistical offices, the international community needs to commit resources to regional statistical offices and to multilateral agencies for the provision of this global public good. 


\section{Notes}

${ }^{1}$ This chapter draws on the proceedings of an HLEG workshop on "The Measurement of Wellbeing and Development in Africa", sponsored by the Government of South Africa, the Japanese International Cooperation Agency, Columbia University and Cornell University, and held in Durban on 12-14 November 2015 (www.oecd.org/statistics/measuring-economic-socialprogress/HLEG $\% 20$ workshop $\% 20$ on $\% 20$ measurement $\% 20$ of $\% 20$ well $\% 20$ being $\% 20$ and $\% 20$ devel opment $\% 20 \mathrm{in} \% 20$ Africa $\% 20$ agenda.pdf). We wish to thank those who participated in this conference for their contributions.

2 This section draws on the section entitled "Conceptual Foundations of the MDG Process" in Bourguignon et al. (2010).

3 The spectrum inputs-outputs-outcomes is familiar in the evaluation literature. Of course any classification of a continuum into three categories is bound to be problematic, but is useful as an analytical device. An example from infrastructure is concrete as an input to road building, miles of road built as an output, and travel time saved as an outcome. An example from education would be school expenditure as an input, number of students enrolled as an output, and test scores measuring learning as an outcome.

${ }^{4}$ www.oecd.org/statistics/measuring-economic-socialprogress/HLEG $\% 20$ workshop $\% 20$ on $\% 20$ measurement $\% 20$ of $\% 20$ well $\% 20$ being $\% 20$ and $\% 20$ devel opment $\% 20 \mathrm{in} \% 20$ Africa $\% 20$ agenda.pdf.

5 www.slideshare.net/StatsCommunications/hleg-thematic-workshop-on-measurement-of-wellbeing-and-development-in-africa-lorenzo-fioramonti.

6 www.slideshare.net/StatsCommunications/hleg-thematic-workshop-on-measurement-of-wellbeing-and-development-in-africa-joseph-stiglitz. At a more technical level, only if the Lorenz curves of two distributions do not cross can one say that one distribution is unambiguously more or less equal than the other.

7 www.slideshare.net/StatsCommunications/hleg-thematic-workshop-on-measurement-of-wellbeing-and-development-in-africa-sabina-alkire.

8 www.slideshare.net/StatsCommunications/hleg-thematic-workshop-on-measurement-of-wellbeing-and-development-in-africa-william-baahboateng-paper.

${ }^{9}$ But that view seems to privilege formal jobs over productive informal work. The problem is that it is hard to distinguish from the available data truly productive informal sector work that increases the size of the national income pie from work that mostly entails getting a large share of some commons rents.

${ }^{10}$ As an intermediate step between the setting of indicators at the global level and at the national level, initiatives have been launched in different regions in the world. A set of more than 100 sustainable development indicators - structured around ten themes - has been defined at the level of the European Union for over a decade. Two-year monitoring reports (http://ec.europa.eu/eurostat/web/sdi/indicators) are compiled and published by the statistical office of the EU (Eurostat). These reports evaluate progress on the long term (since the year 2000) and on the short term (looking at the last five years). Eurostat is currently reflecting on how to adapt its monitoring activity on sustainable development to the SDGs. In 2013, the Conference of European statisticians (CES) also agreed on a set of recommendations on measuring sustainable development. Based on their experience gained in the European region, UNECE, OECD and Eurostat are now developing a road map on statistics for the SDGs, which will help to structure the statistical reporting in the UNECE region. 
11 www.slideshare.net/StatsCommunications/hleg-thematic-workshop-on-measuring-inequalitiesof-income-and-wealth-ravi-kanbur.

12 www.slideshare.net/StatsCommunications/hleg-thematic-workshop-on-measurement-of-wellbeing-and-development-in-africa-rashad-cassim.

13 www.slideshare.net/StatsCommunications/hleg-thematic-workshop-on-measurement-of-wellbeing-and-development-in-africa-daniel-masolwa.

14 www.slideshare.net/StatsCommunications/hleg-thematic-workshop-on-measurement-of-wellbeing-and-development-in-africa-chukwudozie-ezigbalike.

15 On tools, see OECD (2016) for development and application of SDG measurement tools to OECD countries.

${ }^{16}$ Actually, the need for internationally agreed statistical standards also applies to indicators for monitoring targets which are primarily under the responsibility of the individual countries. Comparing countries and above all combining country information to obtain a global picture requires comparable data.

17 www.slideshare.net/StatsCommunications/hleg-thematic-workshop-on-measurement-of-wellbeing-and-development-in-africa-dean-jolliffe.

${ }^{18}$ For an introduction to decomposition methodology, see Kanbur (2007).

\section{References}

Alkire, S. and J.E. Foster (2011), "Understandings and misunderstandings of multidimensional poverty measurement", The Journal of Economic Inequality, Vol. 9, pp. 289-314.

Alkire, S. et al. (2015), Multidimensional Poverty Measurement and Analysis, Oxford University Press, Oxford.

Atkinson, A.B. (2016), Monitoring Global Poverty: Report of the Commission on Global Poverty, The World Bank, Washington D.C.

Bourguignon, F. et al. (2010), "Millennium Development Goals at Midpoint: Where Do We Stand?", in Kanbur, R. and A.M. Spence (eds), Equity in a Globalizing World, The World Bank for the Commission on Growth and Development, pp. 17-40.

CONEVAL (2010), Methodology for Multidimensional Poverty Measurement in Mexico, www.3ieimpact.org/media/filer_public/2014/02/19/methodology poverty measurement_mexico.pdf.

Deaton, A. (2010), "Price indexes, inequality, and the measurement of world poverty", The American Economic Review, Vol. 100, pp. 5-34.

Deaton, A. and V. Kozel (2005), "Data and dogma: the great Indian poverty debate", The World Bank Research Observer, Vol. 20(2), pp. 177-200.

Doyle, M.W. and J.E. Stiglitz (2014), "Eliminating extreme inequality: A sustainable development goal, 2015-2030", Ethics and International Affairs, Carnegie Council, www.ethicsandinternationalaffairs.org/2014/eliminating-extreme-inequality-a-sustainabledevelopment-goal-2015-2030/. 
Ferreira, F. et al. (2015), "A global count of the extreme poor in 2012: Data issues, methodology and initial results", Policy Research Working Paper No. 7432.

Guio, A.C. and E. Marlier (2016), "Amending the EU material deprivation indicator: Impact on the size and composition of the deprived population", in Atkinson, A.B., A C. Guio and E. Marlier (eds), Monitoring Social Europe, Publications Office of the European Union, Luxembourg.

Jolly, R. (1976), “The world employment conference: The enthronement of basic needs", The Development Policy Review, Vol. A9(2), pp. 31-44.

Kanbur, R. (2007), "The policy significance of inequality decompositions", The Journal of Economic Inequality, Vol. 4, No. 3, pp. 367-374.

Kanbur, R. (1990), "Poverty and development: The human development report and the world development report, 1990", in van der Hoeven, R. and R. Anker (eds.), Poverty Monitoring: An International Concern, St. Martin's Press.

Kanbur, R. and Zhuang J. (2012), "Confronting rising inequality in Asia", theme chapter of Asian Development Outlook 2012, Asian Development Bank.

Lakner, C. and B. Milanovic (2015), "Global income distribution: From the fall of the Berlin wall to the Great Recession", The World Bank Economic Review, Advanced Access, www.gc.cuny.edu/CUNY_GC/media/LISCenter/brankoData/wber_final.pdf.

McCarthy, J. (2013), "Own the goals: What the Millennium Development Goals have accomplished”, Brookings Institution, www.brookings.edu/research/articles/2013/02/21-millennium-dev-goalsmcarthur.

Morris, M.D. (1980), “The physical quality of life index (PQLI)", Development Digest, Vol. 18(1), pp. 95-109.

OECD (2017), Measuring Distance to the SDG Targets: An Assessment of Where OECD Countries Stand, OECD, Paris, www.oecd.org/std/OECD-Measuring-Distance-to-SDG-Targets.pdf.

Ravallion, M. (2014), “An exploration of the international comparison program's new global economic landscape", NBER Working Paper No. 20338, National Bureau of Economic Research.

Ravallion, M. (2011), "On multidimensional indices of poverty”, The Journal of Economic Inequality, Vol. 9(2), pp. 235-248.

Reddy, S.G. and T.W. Pogge (2010), "How not to count the poor", in Anand S., P. Segal and J.E. Stiglitz (eds), Debates On The Measurement Of Global Poverty, pp. 42-85, Oxford University Press, Oxford.

Sen, A. (1985), Commodities and Capabilities, North-Holland, Amsterdam.

Stiglitz, J.E., A. Sen and J.P. Fitoussi (2010), Mismeasuring Our Lives: Why GDP Doesn't Add Up, The New Press, New York.

Stiglitz, J.E., A. Sen and J.P. Fitoussi (2009), Report by the Commission on the Measurement of Economic and Social Progress, http://ec.europa.eu/eurostat/documents/118025/118123/Fitoussi+Commission+report.

Talberth J., C. Cobb and N. Slattery (2006), The Genuine Progress Indicator 2006 - A Tool for Sustainable Development, Redefining Progress, http://rprogress.org/publications/2007/GPI\%202006.pdf. 
United Nations (2015a), The Millennium Development Goals Report 2015, www.un.org/millenniumgoals/2015_MDG_Report/pdf/MDG\%202015\%20rev\%20(July\%201).pdf.

United Nations (2015b), "Transforming our world: The 2030 agenda for sustainable development”, Resolution 70/1 of the UN General Assembly, www.un.org/ga/search/view doc.asp?symbol=A/RES/70/1\&Lang=E.

UNDP (2016), Human Development Report 2016 - Human Development for Everyone, United Nations Development Programme, New York, http://hdr.undp.org/sites/default/files/2016_human_development_report.pdf. 